\title{
Türkiye'nin Stratejik Silah Kapasitesi, Editör: Abdullah Erboğa, İstanbul, Seta Yayınları, 2019, 352 s. ISBN: 978-605-7544-95-7
}

\author{
Adem Çılgıın ${ }^{1}$ (i)
}

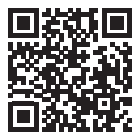

'Sorumlu yazar/Corresponding author: Adem Çılgın, (Yüksek Lisans Öğrencisi), Istanbul Üniversitesi, Sosyal Bilimler Enstitüsü, Avrasya Araştırmaları Anabilim Dalı, İstanbul, Türkiye.

E-posta: ademcilginn@gmail.com ORCID: 0000-0002-6126-1656

Başvuru/Submitted: 18.08 .2020 Kabul/Accepted: 20.08 .2020

Atıf/Citation: Cilgin, Adem. "Türkiye'nin Stratejik Silah Kapasitesi." Abdullah Erboğa'nın Türkiye'nin Stratejik Silah Kapasitesi adlı eserin tanıtımı. Avrasya Incelemeleri Dergisi - Journal of Eurasian Inquiries 9, 2 (2020): 301-307. https://doi.org/10.26650/jes.2020.019

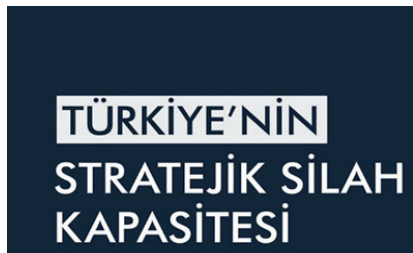

\section{ABDULLAH ERBOĞA}

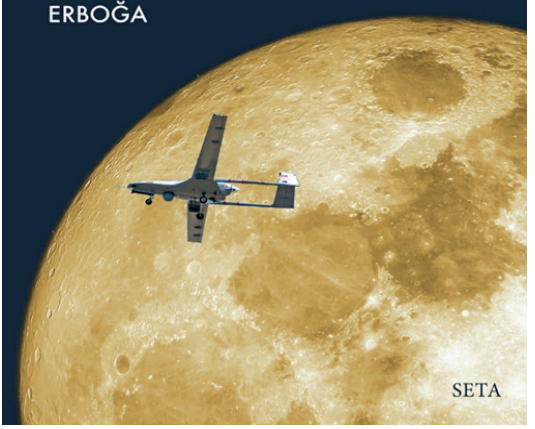

Soğuk Savaş döneminin 1991'de sona ererek, çift kutuplu dünya düzeninin tarihe karışmasıyla beraber, uluslararası siyasi sistem büyük oranda $\mathrm{ABD}$, müttefikleri ve çoğunlukla $\mathrm{ABD}$ güdümünde olan uluslararası örgütlerin hegemonyası altına girmiştir. Ancak gelişimine ve değişimine her an devam eden uluslararası sistem yeni bölgesel-küresel aktörleri beraberinde getirmiştir. Özellikle 2010 yılından itibaren devletlerin gittikçe katılaşan güvenlikçi dış politikaları, birçok ülkede görülen mevcut sistem karşıtı toplumsal hareketler ve büyük oranda işlevini yitirmiş uluslararası örgütler analiz edildiğinde, küresel sistemin ciddi bir dönüşüm süreci içerisinde olduğu araştırmacılar tarafından kabul görmektedir. Bu konjonktür göz önüne alındığında, Türkiye'nin silahlanma konusundaki tercihleri hayati önem taşımaktadır. Siyaset, Ekonomi ve Toplum Araştırmaları Vakfı'na mensup yazarların kaleme aldığı ve Kasım 2019'da 
Seta Yayınları bünyesinde yayımlanan Türkiye’nin Stratejik Silah Kapasitesi adlı çalışma, Türkiye'nin kısa ve orta vadede silahlanma stratejisine odaklanmakta ve Türkiye Milli Askerî Stratejisi'ne (TÜMAS) sivil bir katkı sağlamayı amaçlamaktadır. Çalışmada bahsedilen stratejik silahlardan kasıt nükleer silahlar ve yapay zeka gibi yeni nesil savaş teknolojisi dışında kalan ancak klasik konvansiyonel silahlardan daha fazla değere ve stratejik öneme sahip olan silah sistemleridir. Çalışma stratejik silahlanma konusunda siyasi analiz yapmayı amaçladığından teknik ve mühendislik alanında detaylı bir değerlendirmeye gidilmemiştir.

Abdullah Erboğa'nın editörlüğünü üstlendiği ve Seta Yayınları Strateji Araştırmaları Serisi'nin 12. kitabı olma özelliğini taşıyan çalışma, editör de dâhil olmak üzere beş yazarın kaleme aldığg beş ana bölümden oluşmaktadır. Ek olarak Abdullah Erboğa, "Giriş” bölümünde stratejik silahlanma konusundaki tercihlerin önemine değinerek kitaptaki makaleler hakkında değerlendirmelerde bulunmuş, "Sonuç” bölümünde ise kitap içerisinde Türkiye'nin silahlanma stratejisi üzerine verilen kısa ve orta vadeli tavsiyeleri hatırlatarak, bu tavsiyelere uyulması hâlinde Türkiye'nin askerî teknoloji alanında bölgesinde güçlü bir aktör olacağını ifade etmiştir. “Takdim” bölümünde ise SETA Genel Koordinatörlügü görevini yürüten Prof. Dr. Burhanettin Duran, çalışmanın Türkiye'nin silahlanma stratejisi açısından önemine değinmiştir.

SETA Strateji Araştırmaları Direktörlüğünü yürüten Doç. Dr. Hasan Basri Yalçın’ın kaleme aldığı "Stratejik Silah Kapasitesi” başlıklı birinci bölümde devletlerin stratejik silah tercihlerinin nasıl kurgulanacağı üzerine erişilebilirlik ilkesi temelinde teorik bir çerçeve oluşturulmaktadır. Yalçın, stratejik silah konusunun devletler için hayati öneme sahip olmasına rağmen, bu alandaki araştırmaların silah tercihi meselesini devletlerin stratejik amaçlarının bir sonucu olarak gördüğünü, silah tercihini merkeze alan çalışmaların ise teknik ayrıntılarda kaybolduğunu vurgulamaktadır. Askerî teknolojinin devletlerin strateji planlamasında kritik öneme sahip olduğunu ve bu planlamada askerî teknoloji alanının öncelik taşıması gerektiğini belirtmektedir. Bu bağlamda devletlerin stratejik tercihlerini belirlemesi gereken unsurun amaçlar veya yöntemlerden ziyade araçların, yani silah teknolojilerinin olmasının daha doğru bir karar olacağını savunmaktadır. Belirttiği argümanlar ışığında Yalçın, devletlerin elde etmeye çalıştığı siyasi hedefler ve bu siyasi hedefler uğruna takip edilecek askerî yöntemler ve askerî yöntemler için kullanılacak silah türleri arasındaki ilişkinin stratejik bir mantığa uygun olarak kurgulanması gerektiğini ifade etmektedir. Yalçın'a göre devletler otonom bir güç sahibi olmak istiyorsa ve kendi kaynakları buna nadiren izin veriyorsa taklit, teknoloji transferi, çeşitlendirilmiş satın alma, ortak projeler, sürdürülebilirlik yatırımları gibi farklı yöntemleri deneyebilir. Yalçın, teknoloji ve silah ilişkisinin ele alınış biçimi üzerine de kapsamlı bir literatür değerlendirmesini yapmaktadır. Devletlerin stratejik silahlara erişim kapasitesinin askerî doktrinlerini belirlediğini hatırlatan Yalçın, bu silahların tek başlarına saldırgan veya savunmacı doktrin için sınıflandırılmasının mümkün olmayacağını verdiği örnekler ve yaptığı atıflarla dile getirmiştir. Bu nedenle silah sistemlerinin hepsini tek tek ele almak yerine genel bir sınıflandırma yapılması gerektiğini belirtmektedir. Böylece silah teknolojilerinin birbiriyle uyumlu bir şekilde kurgulanarak askerî 
doktrinin şekillenebileceğini vurgulamaktadır. Makalesinde stratejik silahlanma tercihlerinin nasıl şekillenmesi gerektiği üzerine teorik bir deneme ortaya koymuş olan Yalçın son olarak, teknolojik kapasiteyi merkeze alan silahlanma stratejisinin çok daha gerçekçi bir yaklaşım olduğunu ifade etmektedir. Kullanışlı bir stratejik planlama yapmak isteyen devletlerin mutlak bir teknolojik otonomi geliştirmese bile erişilebilirlik ilkesi çerçevesinde belli derecede bir özerklik elde edebileceği iddiasında bulunmaktadır.

SETA Strateji Araştırmaları Direktörlüğü araştırmacılarından Abdullah Erboğa'nın yazdığ1 “Türkiye'nin Stratejik Silah Kapasitesi ve Silahlanma Stratejisi” başlıklı ikinci bölümde, etkin ve güçlü bir aktör olmanın yolunun yerli silah sistemlerine sahip olmaktan geçtiği iddia edilmektedir. Bu nedenle Türkiye'nin savunma stratejisi bağlamında özgün bir silahlanma stratejisi oluşturması ve bu stratejiyi istikrarlı bir şekilde yürütmesi gerektiği vurgulanmaktadır. Ayrıca makalede Türkiye'nin savunma stratejisinin entegre unsurlarından biri olan silahlanma konusunda önümüzdeki süreçte nasıl bir strateji takip etmesi ve bu stratejiye uygun ne tür bir planlama içerisinde olması gerektiği de tartışılmaktadır. Erboğa, Türkiye'nin yerli silah sistemlerine yönelirken takip etmesi gereken stratejiyi de ele almaktadır. Bu bağlamda hangi silah sistemlerinin stratejik önceliğe sahip olduğunun nasıl belirleneceği sorusu da yazarın dikkat çektiği noktalardan biridir. Türkiye'nin askerî teknoloji serüveni, savunma sanayisi alanındaki vizyonu, silah tedarikindeki öncelikleri ve nihayetinde silahlanma stratejisi analitik bir bakışla irdelenmektedir. Dünya üzerindeki çok az ülkenin yerli silah sanayisinde başarı gösterebildiğini ve bu sayede diğer ülkelere karşı büyük bir üstünlük kurabildiğini belirten Erboğa, askerî teknolojide bağımsız olmak isteyen devletlerin sırasıyla silah sistemlerini doğrudan ithal etme, bakım ve onarım, montaj, alt parça üretimi, sınırlı modifikasyon, ileri düzey silah sistemleri geliştirme aşamalarından geçerek amaçlarına ulaşabileceklerini hatırlatmaktadır. Türkiye'nin ise bu aşamaların birçoğunu geride bırakarak ortak üretim ve kısmi tasarımdan, özgün tasarımların oluşturulduğu projelere geçiş yaptığının altını çizmektedir. Yazar, gelinen noktanın değerli olduğunu belirtmekle beraber Türkiye'nin, rekabet ettiği devletlerin, bilhassa küresel aktörlerin gerisinde kaldığına da değinmektedir. Bu nedenle Türk savunma sanayisi için ileri düzey teknoloji yatırımlarının gerekli olduğunu savunan Erboğa, öncelikli olarak AR-GE için ayrılan payın istikrarlı bir şekilde artırılması ve en az yirmi yıl boyunca dünyada en fazla AR-GE yapan ülkelerden biri olunması gerektiğini vurgulamaktadır. Erboğa, Türkiye'nin silahlanma altyapısını oluşturacak temel kriterlerin belirlenmesinde izlenecek yol haritası açısından üç temel ilkeyi ön plana çıkarmaktadır. Bunlardan ilki, yerli üretim aşamasında geniş bir silah sistemi yelpazesi içerisinden seçim yapılacak olmasından dolayı belli bir düzeyde altyapısı bulunan silah teknolojilerine yatırım yapılması durumu, yani “erişilebilirlik” ilkesidir. İkinci unsur ise tercih edilen silah sistemlerinin Türkiye'nin öncelikli olarak bölgesindeki caydırıcılığını, savunma ve saldırı kapasitesini artıracak nitelikte olması yani "stratejik üstünlük” sağlayacak sistemler kurmasıdır. Üçüncü ilke ise Türkiye'nin kısa ve orta vadede edinebileceği stratejik silah sistemlerine yönelmesi sonucunda bölgesindeki rakiplerine karşı en etkin süre zarfında 
üstünlük kurabilme fırsatını vereceği öngörülen “asgari müddet”tir. Ayrıca yazar, Türkiye’nin iddialı dış politikaya sahip olduğu hemen hemen her dönemde karşılaştığı ambargo çıkmazından kurtulabilmesinin ancak detaylandırılmış bir silahlanma stratejisi oluşturmasıyla mümkün olduğu düşüncesini de savunmaktadır.

Merve İ. Dilek'in kaleme aldığ 1 “Türkiye'nin Stratejik Silah Kapasitesi: İnsansız Hava Araçları” başlıklı üçüncü bölümde İHA sistemlerinin tarihsel gelişimi, dünyada ve Türkiye'de İHA kapasitesi ve kullanımı incelenmekte ve bu sistemlerin operasyonel etkileri üzerinde durulmaktadır. İlk olarak 19. yüzyılın ortasında kullanılmaya başlanan İHA'ların gelişimlerinin 1990'larda hız kazandığı, 2000'lerden itibaren ise çeşitlerinin artarak kullanım alanlarının genişlediği belirtilmektedir. Uzun vadede birçok ülkenin askerî planlamasını insansız savaş uçakları üzerine kurduğu hatırlatılarak, İHA sistemlerinin hem askerî hem de sivil alandaki değer ve potansiyeline değinilmektedir. Ardından İHA'lara entegre edilerek bu geniş sistemlerin oluşmasını sağlayan faydalı yükler, kontrol unsurları, veri linkleri, destek unsurları ve insan unsuru bileşenlerinin özelliklerine değinilerek, İHA sistem unsurları anlatılmaktadır. Bu bileşenlerin sistem içerisindeki kullanım biçimleri ve özelliklerine göre İHA'ların sınıflandırması yapılmakta ve bu araçlar Küçük, Taktik/Operatif ve Stratejik olmak üzere üç ana başlık altında değerlendirilmektedir. Ayrıca söz konusu sistemlerin kullanım alanları, sağladığı avantajlar ve teknik kısıtlamalar incelenmektedir. Yazar İHA'ların avantajlarının ve teknik kısıtlamalarının kategorize edilmesi konusunda farklı görüşler olduğunu belirtmesinin ardından güç koruma, otonomi, yüksek görüntü kalitesi ve veri aktarımı unsurlarını İHA sistemlerinin avantajları içerisinde kategorize ederek detaylandırmaktadır. Veri linklerine bağlılık, bant genişliğine bağlılık ve hava savunma sistemlerine bağlı olarak kullanım alanı sınırlaması unsurlarını ise bu sistemlerin kısıtlamaları içerisinde göstermektedir. Makalenin devamında İHA'ların dünyadaki gelişimi, küresel ve bölgesel güçlerin İHA geliştirme ve üretme kapasitesi ve kullanım alanları da ele alınmaktadır. İlk olarak bu alanda lider küresel aktör olan ve on bir bini aşkın İHA'yı envanterinde barındıran ABD'nin MQ-1 Predator, Reaper MQ-9 ve RQ-4 Global Hawk İHA'ları önde gelen İHA modelleri olarak değerlendirilmektedir. Pentagon'un İHA teknolojisindeki üstünlüğünü elinde tutmak amacıyla bu alandaki yatırımlarını artırdığının altı çizilerek, ABD'nin insansız tanker uçaklarının ve toplu biçimde hareket edebilen "casus" mikro İHA sürülerinin tasarım ve üretim faaliyetlerine hız verdiği hatırlatılmıştır. Dilek, bölgesel bir aktör olarak İsrail' in uzun yıllardır İHA teknolojileri alanında yatırım yapmakta olduğunu ve Heron TP, Hermes 900 ile Hermes 450 MALE sınıfı İHA'larla İHA teknolojileri sıralamasında ABD'den sonra geldiğini belirtmektedir. Dilek'e göre İHA teknolojileri alanında ön plana çıkan bir diğer önemli devlet ise son on yılda İHA üretimi yarışına hızlı bir şekilde dâhil olan ve Füze Teknolojileri Kontrol Rejimine taraf olmamasından dolayı ihracat kısıtlamalarına maruz kalmayan Çin'dir. Küresel bir aktör olarak Çin, geliştirdiği CH-5 ve Wing Loong İHA sistemleri, jet motorlu Cloud Shadow SİHA sistemi ve AT200 insansız kargo uçağıyla bu alanda dikkat çekmektedir. Bir sonraki kısımda İHA alanındaki küresel gelişmeler doğrultusunda Türkiye'nin 
İHA geliştirme ve üretme kapasitesi, terörle mücadelede İHA kullanımı ve muhtemel bir savaş ya da operasyonda İHA gücünü nasıl kullanılabileceği tartışılmaktadır. Ardından İHA'ların askerî ve stratejik değeri ile askerî açıdan taşıdığı potansiyel ortaya konulmaktadır. İHA sistemlerinin hem savunma hem de saldırı amacıyla kullanılabildiği ancak saldırı amacıyla kullanıldığında çok daha fazla stratejik öneme sahip olduğu da vurgulanmaktadır. Özellikle hassas güdümlü füzelerle donatılmış silahlı insansız hava araçlarının (SİHA) hedef tespit etme, hız ve manevra kabiliyetleri bakımından önemli saldırı araçları olduğu savunulmaktadır. Son kısımda ise Türkiye'nin İHA teknolojisine erişebildiği ve bu teknolojinin geliştirilmeye açık bir askerî sistem olduğu belirtilmektedir. Hâlihazırda İHA teknolojisinin ulusal boyutta geldiği nokta ve yakaladığı ivmenin ürün kapasitesi ve çeşitliliğinin artırılması için kritik önemde olduğu, bu doğrultuda İHA geliştirme faaliyetlerine yapılan yatırımların artarak sürdürülmesi gerektiği üzerinde durulmaktadır.

“Türkiye'nin Stratejik Silah Kapasitesi: Füze Sistemleri” başlıklı dördüncü bölümde Bekir İlhan, füze sistemleri üzerine analiz ve tavsiyelerde bulunmuş ve mevcut füze sistemlerine ek olarak Türkiye'nin füze kapasitesini değerlendirmiştir. Bu bölümde ilk olarak füzelerin ayırt edici özellikleri tanıtılmakta ve bir füze sistemini oluşturan dört entegre unsur olan; tahrik sistemi, güdüm sistemi, aerodinamik bileşenler ile savaş başlı̆̆ üzerine genel bir bilgilendirme yapılmaktadır. Ardından stratejik anlamda diğer füze sistemlerine göre daha etkin olan seyir füzeleri (cruise) ile balistik füzelerin özellikleri ve kullanım alanları örneklendirilerek detaylı biçimde ele alınmakta, füze teknolojisinin gelişiminin ardındaki nedenler açıklanmakta ve dünyada füze geliştirme programına sahip olan ülkelerin füze kapasiteleri incelenmektedir. İlk olarak küresel güçler olan ABD, Rusya ve Çin'in füze programlarının gelişimi ve sahip oldukları balistik ve seyir füzeleri ele alınmakta, daha sonra bölgesel güç olarak füze geliştirme programına sahip İran, İsrail, Hindistan ve Pakistan'ın füze kapasitesi detaylandırılmaktadır. Son olarak da Türkiye'nin komşularından Suriye, Yunanistan ve Ermenistan'ın envanterinde bulunan füze sistemlerine dikkat çekilmektedir. Makalenin devamında ülkeleri yerli füze geliştirme programlarına yönlendiren iki temel unsurun tek ve çok taraflı bağımlılıktan kurtulma gayesi ile uluslararası stratejik silah ticaretindeki kontrol ve kısıtlama mekanizmaları olduğunun altı çizilmektedir. Sonrasında Türkiye'nin seyir ve balistik füze kapasitesi ele alınmaktadır. İlk aşamada, ROKETSAN ve TÜBITTAK SAGE tarafından geliştirilerek operasyonel anlamda kullanıma sokulmuş olan yerli füze sistemlerinin yanı sıra, belirtilen kurumlar tarafından henüz geliştirilmekte olan yerli füze sistemleri tanıtılmaktadır. Burada Türkiye'nin seyir ve balistik füzeleri ile hava savunma sistemlerinin geliştirilmesinde hangi aşamada olduğu yerli füze örnekleri üzerinden ele alınmaktadır. İkinci olarak TSK envanterinde bulunan yabancı menşeli füze sistemlerinin özellikleri üzerinde durulmaktadır. Sonrasında ise füze sistemlerinin stratejik değeri savunma, saldırı ve caydırıcılık alanlarındaki işlevlerine göre tartışılmakta ve Türkiye'nin hem kendi imkanları hem de uluslararası sistemin kaotik yapısı içerisindeki zorlama ve fırsatları göz önüne alındığında hangi füze sistemlerine neden yatırım yapması 
gerektiği konusu irdelenmektedir. Füze ve füze sistemlerinin stratejik değerinin, caydırıcılığa yaptığı katkıyla ilişkili olduğunu belirten İlhan, Türkiye'nin müttefikleriyle yaşadığı sorunlar ve bölgesindeki ülkelerin elinde bulunan balistik füze tehditleri göz önünde bulundurulduğunda, misilleme kapasitesini her zaman hazır tutması gerektiğini hatırlatmaktadır. Yazar, Türkiye'nin yerli üretim balistik füze menzilinin rakiplerine kıyasla yetersiz kaldığını, ancak balistik füzelerin caydırıcılık oranının kitle imha silahı taşıyıp taşımadığına bağlı olduğunu belirtmektedir. İlhan’a göre, Türkiye kitle imha silahına sahip olmamasından dolayı orta ve uzun menzilli balistik füzelerden ziyade, savunmaya dayalı caydırıcılığı arttıracak hava ve balistik füze savunma sistemlerine önem vermelidir. İlhan, bahsi geçen balistik füze savunma sistemlerinin ileri ve hassas teknoloji gerektirmesinden dolayı kısa vadede yerli üretimin mümkün olmayacağını hatırlatmaktadır. Dolayısıyla, uzun vadede hava ve balistik füze savunma sistemlerin yerli üretimi için çalışmaların devam etmesinin, kısa vadede ise Türkiye'nin acil güvenlik ihtiyaçları doğrultusunda teknoloji transferi önceliğiyle bu sistemleri satın almasının, savunmaya dayalı caydırıcılık stratejisini güçlendireceği düşüncesi, yazarın ortaya koyduğu temel argümandır.

SETA Stratejik Araştırmalar Direktörlüğü Araştırma Asistanı Merve Dilek Dağdelen'in kaleme aldığı “Türkiye'nin Stratejik Silah Kapasitesi: Uydu ve Uzay Teknolojisi” başlıklı beşinci bölümde, uydu ve uzay teknolojilerinin mevcut askerî kapasitenin daha etkin, hızlı ve kesin sonuçlara götürecek bir şekilde kullanılması yönünde önemli bir unsur olarak öne çıkması ele alınmaktadır. Dağdelen, uyduları kullanıcı türlerine göre sivil, ticari, hükümet, askerî veya birden fazla alana hizmet verenler olmak üzere sınıflandırmaktadır. Makalede büyük oranda hükümet amaçları ve askerî amaçlar için kullanılan ve stratejik öneme sahip olduğu düşünülen uydular analiz edilerek, uydu ve uzay teknolojisinin askerî alanda getirdiği yenilik ve imkanlar tartışılmaktadır. Dağdelen'e göre uydular ve uzay teknolojisinin askerî alanda üç önemli stratejik katkısı vardır: Ulusal güvenlik, istihbarat faaliyetleri ve etkin operasyon yürütme kapasitesi. Bu sistemler bir yandan barış zamanında istihbarat faaliyetlerine yaptığ katkıyla önleyici tedbirlerin alınmasında önemli bir görev üstlenirken diğer yandan savaş zamanında bir ordunun hava, kara, deniz ve diğer tüm kuvvetlerinde gerek birliklerin sevk ve idaresi gerekse iletişiminde etkin bir şekilde kullanılmasına imkân tanımaktadır. Dağdelen, uydu ve uzay teknolojisinin bir ülkenin ordusunun askerî gücü ve kapasitesinin çarpanı olan başlıca araçlardan biri olduğunu belirtmektedir. Yazar, Türkiye'nin stratejik silah kapasitesi bakımından uydu ve uzay teknolojisinin etkisini ve önemini incelediği bölümde ilk olarak uydu sistemlerinin genel özellikleri bağlamında bu teknolojinin nasıl doğduğuna da değinmektedir. Uyduların çalışma prensiplerini genel olarak kavrayabilmek adına yörüngelerine göre nasıl sınıflandırıldıkları ve sık karşılaşılan yörünge türlerinin özelliklerinden bahsetmektedir. Sonrasında geleneksel savaşma biçimini dönüştürdüğü belirtilen uzay tabanlı sistemlerin ordulara katkısı, hem barış zamanı hem de savaş zamanı açısından ortaya koyulmaktadır. Dağdelen, uzayın silahlanması anlamında yaşanan gelişmelere dair bilgiler aktarmaktadır. Dünya yörüngesinde sayısı 2062'yi bulan uyduların askerî amaçlar için kullanılan türlerini, küresel ve bölgesel aktörlerin sahip 
oldukları askerî uydular açısından ele almaktadır. Son olarak Türkiye'nin uydu ve uzay teknolojisinde, bu alanda gelişmekte olan bir ülke olarak hangi aşamada olduğunu örneklerle beraber aktarmaya çalışmaktadır. Dağdelen, kritik öneme sahip uydu bileşenleri, yazılımlar ve alt sistemlerin millileştirilmesi hedefinin gerçekleşmesi durumunda, Türkiye'nin uydu teknolojisi alanında dışa bağımlılığının büyük oranda azalacağını öngörmektedir. Özellikle 2018'de kurulmuş olan Türkiye Uzay Ajansı'nın bu alanda oluşturacağı kurumsallaşmanın, orta ve uzun vadede Türkiye'nin başta askerî alanda olmak üzere ihtiyaç duyduğu ve duyacağ uydu ve uzay sistemleri projelerini sistematik bir şekilde hayata geçirebilmesine yardımcı olacağına değinmektedir. Yazar, Türkiye'nin uydu ve uzay teknolojisi alanında öncelik vermesi gereken projelerin sırasıyla uydu firlatma merkezi ve bölgesel konumlama ve zamanlama uyduları olduğunu ifade etmektedir. Dağdelen’e göre Türkiye uzayda kalıcı bir güç oluşturmak istiyorsa, hem teknik hem de yönetimsel alanda uydu ve uzay teknolojilerinde gelişmiş ülkelerin deneyimlerinden faydalanmalı ve bu alanda faaliyet gösteren kişilerin sayısını artırılarak kurumların sürdürülebilirliğini sağlanması gerekmektedir.

Sonuç olarak bir bütün hâlinde incelendiğinde bu çalışma, mühendislik literatürüne boğulmaması ve silah sistemlerini güvenlik ve uluslararası ilişkiler perspektifinden anlaşılır biçimde analiz etmesiyle ön plana çıkmaktadır. Türkçe kaynakların yanı sıra, stratejik silahlanma alanında otorite olarak kabul edilen birçok İngilizce kaynaktan yararlanılması dikkat çekmektedir. Çalışma, bazı durumlarda askerî kabiliyetin siyasi hedefleri elde edebilmek için araç olarak kullanıldığını ve bu tip siyasi hedeflerin askerî kapasitenin baz alınarak belirlenmesi gerektiğini savunmaktadır. Bu bağlamda kitapta yer alan makalelerde Türkiye'nin silah stratejisi anlamında iyi analiz edilmiş, tutarlı ve istikrarlı bir yol haritası çizmesi gerektiği belirtilmektedir. Bu nedenle Türkiye'nin ekonomik imkanlarının ve yerli üretim kabiliyetinin, çok sayıdaki silah teknolojileri arasından en işlevsel olanlara yöneltilmesi gerektiği savunulmuştur. Dünya üzerinde birçok gelişmiş silah teknolojisinin bulunduğu ve Türkiye'nin mevcut imkanlarıyla bu silah teknolojilerinin hepsini üretme ihtimalinin olmadığ vurgulanmış, ancak silahlanma konusunda satın alma, ortak üretim ve teknoloji transferi gibi farklı alternatiflerin de bulunduğu hatırlatılmış ve silahlanma stratejisi konusunda bu alternatifler irdelenmiştir. Çalışma, Türkiye'nin silahlanma stratejisinde kısa ve orta vadede erişebileceği gelişmiş askerî sistemlere odaklanması gerektiğini, bu sayede bölgesinde başat aktör olacağını belirtmektedir. Gelişmekte olan bir ülke olarak Türkiye'nin yerli silah sistemlerinin üretiminde izlemesi gereken stratejinin ana hatları ortaya konulmuş ve silah stratejilerinin belirli öncelikler baz alınarak geliştirilmesinin altı çizilmiştir. Stratejik silah kapasitesi üzerine önemli analiz ve tavsiyelerde bulunan eser, bu alanda sivil bir çalışma olarak bayrak taşıyıcı bir rol üstlenmektedir. 
